PANCREATITIS

\title{
Detection and identification of bacterial DNA in serum from patients with acute pancreatitis
}

\author{
E de Madaria, J Martínez, B Lozano, L Sempere, S Benlloch, J Such, F Uceda, R Francés, \\ M Pérez-Mateo
}

See end of article for authors' affiliations

Correspondence to:

Correspondence to:

Sección Aparato

Digestivo, Hospital

General Universitario de

Alicante, Pintor Baeza $\mathrm{s} / \mathrm{n}$

03010 Alicante, Spain;

perezmateo_mig@gra.es

Revised version received

17 November 2004

Accepted for publication

18 January 2005
Background and aims: Bacterial infections are common complications in patients with acute pancreatitis, and translocation of bacteria from the intestinal lumen is probably the first step in the pathogenesis of these infections. As blood cultures in afebrile patients are usually negative, more sensitive methods to investigate this hypothesis in patients are needed. Our group has recently developed a method to detect the presence of bacterial DNA in biological fluids, and we aimed to detect bacterial DNA in patients with acute pancreatitis, as molecular evidences of bacterial translocation.

Methods: Samples of blood were obtained on three consecutive days within the first six days after admission. Bacterial DNA was detected using a polymerase chain reaction based method, and an automated DNA nucleotide sequencing process allowed identification of bacteria species.

Results: Thirty one consecutively admitted patients with acute pancreatitis were studied. Bacterial DNA was detected in six patients (19.3\%), and the sequencing process allowed identification of Citrobacter freundii and Pseudomonas aeruginosa. In two patients the same bacteria detected at admission was detected 24 hours later (above $99.9 \%$ homology of nucleotide sequence). Basic clinical and biochemical characteristics were similar among patients with or without the presence of bacterial DNA.

Conclusion: Detection of gram negative bacteria derived bacterial DNA in our series supports the contention that bacterial translocation is a systemic process in approximately $20 \%$ of patients with acute pancreatitis that does not seem to be related to the severity of the episode or immediate development of infection.
A cute pancreatitis (AP) is a frequent cause of hospital admission. Most AP episodes are mild with a low morbidity and almost no mortality. However, approximately $20 \%$ of AP episodes are severe, and in these patients mortality may be as high as $20 \% .^{12}$ A third of patients with severe AP develop infectious complications that may explain up to $50 \%$ of deaths. ${ }^{3-7}$

Infection of pancreatic and peripancreatic tissue in the course of severe AP occurs most frequently in patients with extensive pancreatic necrosis. An infected necrosis is an extremely severe complication, leading to death of the patient in almost $50 \%$ of cases. $^{8-10}$ Although the reasons why pancreatic necrosis may become infected remain debatable, experimental evidence supports the hypothesis of bacterial translocation (BT) as the main pathogenic mechanism. BT is an incompletely understood process that has been defined as the passage of bacteria from the intestinal lumen to mesenteric lymph nodes and other organs, ${ }^{11}$ and that has been demonstrated in animal models of AP. ${ }^{12-15}$ Several lines of evidence support the contention of BT related to the development of infections in AP: firstly, most infections in this setting are caused by Gram negative bacteria (GNB), usually colonising the intestinal lumen; secondly, endotoxaemia is a common event in patients with severe $\mathrm{AP}^{16}{ }^{17}$; and finally, abnormal intestinal permeability (as an expression of deterioration in the barrier function of the intestine) has been described in patients with severe AP. ${ }^{18-20}$

It is not known the route by which bacteria from the intestinal lumen can get access to pancreatic necrosis. Theoretically, bacteria could follow a haematogenous route spreading to different organs, and probably colonise those with an abnormal capacity to mount an adequate bactericidal response. However, in this case one would expect to detect bacteria in blood by means of routine blood cultures, but this is not the rule, even in patients with proven infected pancreatic tissue. ${ }^{21}$ Alternatively, translocating bacteria may be opsonised, being unable to grow in conventional cultures.

However, even in cases of bacterial opsonisation, the remainder of the bacterial wall or inner components of bacteria may remain in blood. Bacterial DNA (bactDNA) is a stable component of bacteria, and our group has previously reported the development of a highly sensitive and specific polymerase chain reaction (PCR) based method to detect minimal amounts of bactDNA in serum from patients with cirrhosis. $^{22}$ By means of this methodology, we intended to detect and then identify the bacterial origin of the hypothetical episodes of BT in patients with AP.

\section{PATIENTS AND METHODS}

AP was defined as the presence of compatible abdominal pain together with an increase in plasma amylase three times above the upper limit of normality, and abnormal pancreatic morphology on image techniques. The severity of the episode was determined according to the Atlanta criteria. ${ }^{23}$ Prediction of severity was done by means of the APACHE-II criteria. ${ }^{24}$ Patients with a score $\geqslant 8$ received prophylactic intravenous antibiotics (imipenem $500 \mathrm{mg}$ three times daily) for at least two weeks and dynamic contrast enhanced computed tomography was performed. An abdominal ultrasound was carried out in patients with mild AP as a single image technique if the clinical situation was adequate. The Balthazar score was used to describe radiological findings ${ }^{25}$

Abbreviations: $\mathrm{AP}$, acute pancreatitis; $\mathrm{BT}$, bacterial translocation; GNB, gram negative bacteria; bactDNA, bacterial DNA; PCR, polymerase chain reaction; $C R P, C$ reactive protein; $b p$, base pairs 
and the presence or absence of pancreatic necrosis. Pancreatic necrosis was defined as focal or diffuse well marginated zones of non-enhanced pancreatic parenchyma that were larger than $3 \mathrm{~cm}$ or involved more than $30 \%$ of the area of the pancreas. ${ }^{23} \mathrm{C}$ reactive protein (CRP) was measured 48 hours from admission in all patients, and all local and systemic complications were recorded.

Blood from each patient was obtained for routine haematological, biochemical, and coagulation studies. Blood was inoculated at the bedside in aerobic and anaerobic blood culture bottles, $10 \mathrm{ml}$ each, and in rubber sealed pyrogen-free tubes of $5 \mathrm{ml}$ each (Endo Tube ET; Chromogenix AB, Vienna, Austria). Subsequent blood samples were collected under aseptic conditions every 24 hours over a three day consecutive period within the first six days after hospital admission and inoculated in rubber sealed pyrogen-free tubes (Endo Tube ET; Chromogenix AB).

\section{DNA isolation}

DNA extraction and PCR amplification of the complete 16S ribosomal RNA gene were performed in all serum samples using the method described previously by our group..$^{22}$

After blood extraction, specimens were processed in airflow chambers and tubes were never exposed to free air. All laboratory procedures were performed by the same investigator (BL). Serum was obtained by centrifuging blood at $3500 \mathrm{rpm}$ for 10 minutes. DNA was extracted with a QIAmp DNA Mini Kit (Qiagen, Hilden, Germany) from $200 \mu \mathrm{l}$ of serum incubated in AL buffer with proteinase K for 30 minutes at $56^{\circ} \mathrm{C}$, and applied onto QIAmp Spin Columns. Samples were microcentrifuged at full speed (13000 rpm) and DNA was finally eluted with $50 \mu \mathrm{l}$ of $70^{\circ} \mathrm{C}$ preheated AE buffer. The yield and purity of DNA were measured by reading $\mathrm{A}_{260}$ and $\mathrm{A}_{260} / \mathrm{A}_{280}$ in a BioPhotometer (Eppendorf).

The sensitivity, specificity, and limit of detection of the method have been determined previously, ${ }^{22}$ with an absolute limit of bactDNA detection of $10 \mathrm{pg} / \mathrm{ml}$.

\section{DNA amplification}

PCR reactions for the complete amplification of the $16 \mathrm{~S}$ ribosomal RNA gene were carried out. Universal primers were: 5'-AGA GTT TGA TCA TGG CTC AG-3' as forward (located at positions 8-27) and 5'-GGT TAC CTT GTT ACG ACT T-3' as reverse (positions 1509-1491). ${ }^{26}$ Approximately 10-100 ng of template were added into a reaction mix containing $20 \mathrm{mM}$ Tris $\mathrm{HCl}(\mathrm{pH} 8.4), 50 \mathrm{mM} \mathrm{KCl}, 1.5 \mathrm{mM}$ $\mathrm{MgCl}_{2}, 200 \mu \mathrm{l}$ of each deoxynucleoside triphosphate, $0.4 \mu \mathrm{M}$ of each primer, and 2.5 U Taq DNA Polymerase (Invitrogen, Life Technologies, Carlsbad, California, USA) to complete a final volume of $50 \mu \mathrm{l}$.

To avoid false positive results, positive and negative controls were performed in duplicate in each assay. DNA from Escherichia coli was added as a positive control, and sterile water and PCR mixtures (without template) were used as negative controls. PCR was carried out in a Mastercycler personal (Eppendorf) through the cycles as follows: an initial cycle of $95^{\circ} \mathrm{C}$ for four minutes was followed by 35 cycles of $94^{\circ} \mathrm{C}$ for 30 seconds, $55^{\circ} \mathrm{C}$ for 30 seconds, and $72^{\circ} \mathrm{C}$ for 90 seconds, with a final extension period at $72^{\circ} \mathrm{C}$ for 10 minutes to complete the cycling sequence. Total PCR reaction volume was filtered through QIAquick Spin Columns (QIAquick PCR Purification Kit; Qiagen) to remove primers and nucleotides.

Purified products $(5 \mu \mathrm{l})$ were visualised on $1.5 \%$ agarose gels stained with ethidium bromide. A band of approximately 1500 base pairs (bp) was obtained, corresponding to the specific amplification of the prokaryotic 16S ribosomal RNA gene.

\section{DNA sequencing}

PCR amplicons were partially sequenced using the ABI PRISM BigDye Terminator v3.1 Cycle Sequencing kit (Applied Biosystems, Foster City, California, USA) and ABI PRISM 310 automated sequencer according to the manufacturer's indications. The same forward primer used for PCR amplification was used for sequencing approximately $600 \mathrm{bp}$.

Obtained sequences were compared with l6S rRNA sequences available both in the Ribosomal Database Project $^{27}$ and the GenBank and EMBL obtained from the National Center for Biotechnology Information Database by the advanced BLAST search ${ }^{28}$ (www.ncbi.nlm.nhi.gov).

\section{Positive control DNA and negative controls}

DNA from clinical isolates of $E$ coli was extracted in an identical manner as bactDNA obtained from blood samples. This DNA was used in PCR reactions to determine if the PCR reaction was successful. In addition to a positive control sample for bactDNA, each PCR experiment contained a negative control that consisted of all PCR reagents in experimental samples but without bactDNA. This safeguarded against the potential contamination of stock PCR reagents with microbial DNA products, which could lead to false positive results.

\section{Statistical analysis}

CRP data are reported as median (25th and 75 the percentiles). Statistical differences were analysed using the $\chi^{2}$ test for categorical data applying the Yates' correction when required or the Mann-Whitney $U$ test for quantitative data. All $\mathrm{p}$ values were two tailed. A p value $<0.05$ indicated statistical significance. Analysis was performed with the SPSS statistical package (SPSS Inc. v 10.0; Chicago, Illinois, USA).

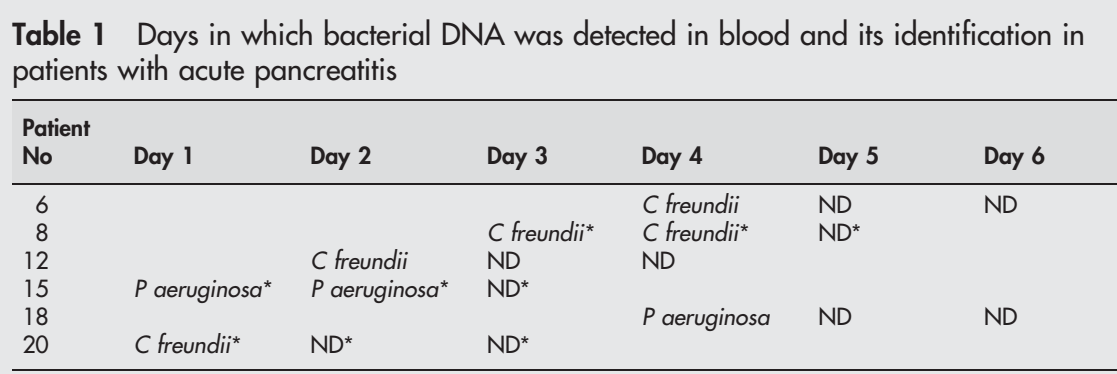

Filled areas represent days on which blood was obtained for culture and bacterial DNA detection (with bacteria detected indicated). ND, no detection of bacterial DNA. Blank areas represent days on which no blood samples were collected. *Samples obtained after the beginning of antibiotic prophylaxis. 


\begin{tabular}{|c|c|c|c|c|c|}
\hline $\begin{array}{l}\text { Patient } \\
\text { No }\end{array}$ & Severity & Aetiology & $\begin{array}{l}\text { Bacterial } \\
\text { identification }\end{array}$ & $\begin{array}{l}\text { Blood } \\
\text { culture }\end{array}$ & Infection \\
\hline 6 & Mild & Biliary & C freundii & - & - \\
\hline 8 & Mild & Idiopathic & C freundii & - & - \\
\hline 11 & Severe & Biliary & - & - & Urinary (E coli) \\
\hline 12 & Mild & Idiopathic & C freundii & - & Respiratory \\
\hline 15 & Severe & Idiopathic & $P$ aeruginosa & - & Pancreatic necrosis ( $E$ coli) \\
\hline 18 & Mild & Ischaemic & $P$ aeruginosa & - & - \\
\hline 20 & Severe & Biliary & C freundii & - & - \\
\hline 29 & Mild & Biliary & - & $S$ epidermidis* & - \\
\hline
\end{tabular}

\section{RESULTS}

From January 2003 to November 2003, 31 consecutively admitted patients with AP were included in this study. Thirteen patients were male, with a mean age 57 (SD 20) years. The aetiology of AP was biliary in 14 cases, alcoholic in six, related to hypertriglyceridaemia in one patient, idiopathic in eight cases, and due to other causes in two patients. The clinical course of AP was mild in 22 patients and severe in the remaining nine cases. Complications related to the episode were one case of aseptic pancreatic necrosis, one case of renal impairment, one respiratory insufficiency, one case of shock, and four pancreatic pseudocysts. Three infections were detected, including one respiratory, one urinary, and one on a pancreatic necrosis, in different patients.

All patients with AP of biliary origin underwent surgery on admission, except for one patient who developed peripancreatic collections progressing to a pancreatic pseudocyst. One patient with infected pancreatic necrosis was treated with imipenem and then underwent early surgery (necrosectomy and set in place of draining tubes), with a good clinical outcome. After surgery only one patient required vasoactive drugs because of hypotension refractory to general measures of plasma volume expansion. The clinical outcome of the remaining operated patients was unremarkable. The patient with respiratory infection responded to therapy with levofloxacin, and the urinary infection recorded in other patient was successfully treated with ciprofloxacin. No patient died during hospitalisation or during the one year follow up.

Table 3 Severity of acute pancreatitis, Balthazar score, presence of necrosis, and C reactive protein (CRP) levels, 48 hours after admission, in patients with and without bacterial DNA (bactDNA) in blood

\begin{tabular}{lll}
\hline & $\begin{array}{l}\text { Positive bactDNA } \\
\text { (n=6) }\end{array}$ & $\begin{array}{l}\text { Negative bactDNA } \\
(\mathbf{n}=\mathbf{2 5})\end{array}$ \\
\hline $\begin{array}{l}\text { Severity } \\
\text { Mild }\end{array}$ & 4 & 18 \\
$\begin{array}{l}\text { Severe } \\
\text { Balthazar }\end{array}$ & 2 & 7 \\
A & 1 & 4 \\
B & 0 & 0 \\
C & 1 & 2 \\
D & 1 & 3 \\
E & 2 & 4 \\
Necrosis & $1 / 6$ & $1 / 25$ \\
CRP (mg/dl) & & 16 \\
$<10$ & 1 & 9 \\
$>10$ & 5 & \\
\hline There were no significant differences between the two groups.
\end{tabular}

\section{Detection and identification of bacterial DNA}

BactDNA was detected in eight samples obtained from six patients with AP (table 1), being mild in four and severe in two cases. Staphylococcus epidermidis was isolated in the only positive blood culture in this series (patient No 29), which we considered was due to skin contamination of the culture, and this patient was not included in the evaluation of patients with translocation. Three of six patients with bactDNA received prophylactic intravenous imipenem (500 mg three times daily) on admittance to the emergency unit. The aetiology of AP was considered idiopathic in three patients, biliary in two, and ischaemic in one case. All PCR fragments were sequenced for bacterial identification. Clinical and microbiological characteristics of the patients in whom BT was detected as well as the results of bacterial DNA identification are detailed in table 2. Citrobacter freundii was detected in patient Nos 6, 8, 12, and 20, and Pseudomonas aeruginosa in patient Nos 15 and 18. Similarity of the isolated bactDNA sequence present in the database was in most cases more than $99 \%$, which is high enough to warrant identification of the species. BactDNA corresponded to the same bacteria in two consecutive samples obtained from patient Nos 8 and 15 (table 1). The similarity of nucleotide sequences isolated in the consecutive samples in both patients was greater than $99.9 \%$.

We did not observe significant differences in Atlanta severity or Balthazar score, presence of necrosis, or CRP levels, 48 hours after admission, in patients with or without molecular evidence of BT (table 3). However, CRP levels showed a trend towards higher levels in patients with bactDNA in blood (median $14.8(12.2-17.6) \vee 5$ (1.5-17); NS).

\section{Infections developed during hospitalisation and its relation to bactDNA detection and identification}

Table 2 shows all infections that developed in patients included in the study, in relation to detection of bactDNA. Patient No 11 developed a urinary infection due to $E$ coli nine days after admission, and bactDNA had not been detected in blood samples. Patient No 12 in whom $C$ freundii had been detected at admission, developed a respiratory infection after nine days of hospitalisation and the responsible microorganism was not identified. Patient No 15 presented with two positive samples for $P$ aeruginosa at admission, and $E$ coli was isolated from the pancreatic necrosis 24 days later.

Prophylactic antibiotic therapy was administered to all nine patients with severe AP, and to one patient with mild AP. As shown in table 1, prophylactic administration of antibiotics did not influence the presence of bactDNA.

\section{DISCUSSION}

In this study, we detected bactDNA in blood of a subgroup of patients with AP, thus providing molecular evidence of BT. Our results suggest that BT is a systemic process, ${ }^{12-15}$ 
developing in a subset of patients with AP, and that this does not seem to be related to the severity of the episode.

$\mathrm{BT}$ from the intestinal lumen may be the main pathogenic mechanism leading to the development of infections in patients with AP. Bacteria of intestinal origin have been isolated in mesenteric lymph nodes, blood, ascitic fluid, and other organs in experimental models of AP. ${ }^{12-15}$ Similarly, administration of either $\mathrm{C}^{14}$ labelled bacteria ${ }^{14}$ or fluorescent microspheres to experimental animals with induced $\mathrm{AP}^{29}$ is followed shortly by its appearance in biological fluids and organs. The route of dissemination may be lymphatic or haematogenous, ${ }^{140}$ and might be related to an impaired intestinal barrier, as shown by the presence of an abnormal intestinal permeability in this setting. ${ }^{182031}$ Furthermore, most of the bacteria commonly responsible for bacterial infections in patients with $\mathrm{AP}$ are Enterobacteriaceae of intestinal origin, ${ }^{10-34}$ and it has been shown that GNB infections in patients with AP are preceded by intestinal colonisation of the same bacteria species. From a different point of view, the risk of developing a septic complication is higher in patients with AP and colonic overgrowth by GNB, and this is associated with increased mortality. ${ }^{35}$ It is likely that changes in the intestinal flora may induce impairment of the intestinal barrier and induction of associated BT..$^{12} 13$

Studies of the presence of bactDNA in biological fluids in patients with AP and other pathologies have rarely been reported in the literature. To our knowledge, only one study investigated the presence of bactDNA in blood in a series of patients with AP. ${ }^{31}$ Similar to our investigation, blood was obtained at three different time points during the first week of admission, and the authors failed to detect bactDNA in any patient. This is surprising given the simultaneous presence of positive blood cultures in some of the patients. This conflicting result may be due to different methodological problems, such as the level of sensitivity of the PCR or the search for bactDNA in whole blood, as it has been reported that both haemoglobin and lactoferrin may inhibit PCR. ${ }^{36}$ As stated in the methods section (see positive control DNA and negative controls) in our investigations all bactDNA negative samples were inoculated with a known amount of bactDNA and tested again to rule out the hypothetical presence of inhibitors of PCR that could induce false negative results.

Our group recently described detection of bactDNA in serum and ascitic fluid from a series of patients with decompensated cirrhosis, ${ }^{22}$ and in a subsequent study the same authors showed that the presence of bactDNA in serum persisted for as long as 72 hours in a different subset of patients with identical clinical characteristics. ${ }^{37}$ The authors considered that persistence of bactDNA in blood was probably the consequence of repeated episodes of BT and not of the predominance of a reduced clearance of bacterial fragments. Interestingly, in both studies detection of bactDNA was not associated with more advanced liver disease or short term development of infection by the same bacteria species.

In the present investigation we detected bactDNA in six of 31 patients with AP. Although it has been reported that BT would be more frequent in patients with severe $\mathrm{AP}^{12-17}$ we did not find any significant relationship between detection of bactDNA and severity of the process, presence of pancreatic necrosis, or associated radiological findings. In only two patients with bactDNA in blood was AP considered severe, according to actual criteria. As the severity of the episode of $\mathrm{AP}$ is the consequence of the clinical evolution, and we do not know what mechanisms are intimately related to the presence in blood of bactDNA in this setting, it is difficult to explain the relationship between BT and the severity of the episode of AP using the present study design.
BactDNA is constituted by short repeated sequences of unmethylated $\mathrm{CpG}$ dinucleotides, known as CpG motifs. Different experimental studies have demonstrated that these fragments are capable of inducing a similar immune response to that produced by a complete microorganism in vitro, ${ }^{38-40}$ thus becoming potent activators of cells of the innate immune system through joining Toll-like receptor $9 .{ }^{41}$ Our group has also shown that bactDNA induces potent macrophagic activation with liberation of proinflammatory cytokines $^{42}$ and this could, in turn, increase the bactericidal activity of the media, making immediate bacterial colonisation less likely. ${ }^{43}$ Taken together, we may hypothesise that BT develops in some patients with AP irrespective of the severity of the process, and that infection may take place in cases were a sufficient number of viable bacteria find the adequate substrate, such as in those with pancreatic necrosis or in patients with decreased activity of the immune system.

Interestingly, CRP levels in patients with bactDNA showed a tendency to be higher than those in patients without bactDNA. CRP is an acute phase protein that has been shown to have prognostic utility in patients with AP. ${ }^{44}$ Increased levels of CRP in patients with bactDNA may be a result of the immune response to the presence of bactDNA or, conversely, one of the causes inducing translocation.

In our series, three of six patients with bactDNA were receiving antibiotic prophylaxis with imipenem. This may be explained by the fact that intravenous imipenem is not excreted in bile and affects only slightly the intestinal flora. ${ }^{45}{ }^{46}$ Furthermore, as our method detects not only viable but also non-viable bacteria in blood, the translocating bacteria, probably killed by plasma levels of antibiotics, may be equally detectable.

The only patient with an infected pancreatic necrosis was due to $E$ coli, when bactDNA from $P$ aeruginosa was detected at admission. This apparent discrepancy may be explained by the time elapsed between bactDNA detection and development of the infection (24 days). It is not known if BT due to a certain bacterial species at a certain time point may be followed by BT by a different bacterial species along the inflammatory process. In fact, abnormal intestinal permeability in patients with AP has been described previously by our group ${ }^{20}$ and others. ${ }^{19}$

C freundii was identified in patient Nos 6, 8, 12, and 20. Although to our knowledge there is no information in the literature regarding the pathogenic role of $C$ freundii in the development of infections in patients with AP, this bacteria has been shown to translocate in different experimental and clinical situations $s^{3748}$ and it is related to both biliary and intra-abdominal infections. ${ }^{49-52}$ As bactDNA detection and identification in patients with AP is a new approach to the study of BT in humans, we do not know if $C$ freundii is a frequent translocating agent in patients with AP.

In conclusion, detection of GNB derived bactDNA in our series supports the contention that BT is a systemic process in approximately $20 \%$ of patients with AP that does not seem to be related to the severity of the episode or associated with an immediate development of infection. More information is needed to ascertain the mechanisms leading to BT and its clinical and immunological consequences in the short and long term in patients with AP.

\section{ACKNOWLEDGEMENT}

This work was supported in part by grants from Instituto de Salud Carlos III, Madrid, Spain (G03/156 and C03/02).

\section{Authors' affiliations \\ E de Madaria, J Martínez, L Sempere, F Uceda, M Pérez-Mateo,} Sección de Aparato Digestivo, Hospital General Universitario, Alicante, Spain 
B Lozano, S Benlloch, R Francés, Sección de Inmunología, Hospital General Universitario, Alicante, Spain

J Such, Unidad Hepática, Hospital General Universitario, Alicante, Spain

Conflict of interest: None declared.

\section{REFERENCES}

1 Banks PA. Infected necrosis: morbidity and therapeutic consequences. Hepatogastroenterology 1991;38:116-19.

2 Buchler MW, Gloor B, Muller CA, et al. Acute necrotizing pancreatitis: treatment strategy according to the status of infection. Ann Surg 2000;232:619-26.

3 Bradley EL III, Allen K. A prospective longitudinal study of observation versus surgical intervention in the management of necrotizing pancreatitis. Am J Surg 1991;161:19-24.

4 Gloor B, Muller CA, Worni M, et al. Late mortality in patients with severe acute pancreatitis. Br J Surg 2001;88:975-9.

5 Gloor B, Muller CA, Worni M, et al. Pancreatic infection in severe pancreatitis: the role of fungus and multiresistant organisms. Arch Surg 2001;136:592-6.

6 Widdison AL, Karanjia ND. Pancreatic infection complicating acute pancreatitis. Br J Surg 1993;80:148-54.

7 Company L, Saez J, Martinez J, et al. Factors predicting mortality in severe acute pancreatitis. Pancreatology 2003;3:144-8.

8 Beger HG, Bittner R, Block S, et al. Bacterial contamination of pancreatic necrosis. A prospective clinical study. Gastroenterology 1986;91:433-8.

9 Bassi C. Infected pancreatic necrosis. Int J Pancreatol 1994;16:1-10.

10 Fedorak IJ, Ko TC, Djuricin G, et al. Secondary pancreatic infections: are they distinct clinical entities? Surgery 1992;112:824-30

11 Berg RD. Bacterial translocation from the gastrointestinal tract. J Med 1992;23:217-44

12 Runkel NS, Moody FG, Smith GS, et al. The role of the gut in the development of sepsis in acute pancreatitis. J Surg Res 1991;51:18-23.

13 Gianotti L MRAJW. Pancreatitis-induced microbial translocation: a study of the mechanisms. Res Surg 1992;4:87-91.

14 Gianotti L, Munda R, Alexander JW, et al. Bacterial translocation: a potential source for infection in acute pancreatitis. Pancreas 1993;8:551-8.

15 Tarpila E, Nystrom PO, Franzen L, et al. Bacterial translocation during acute pancreatitis in rats. Eur J Surg 1993;159:109-13.

16 Martinez J, Palazon JM, Munoz C, et al. Endotoxin and anti-endotoxin antibodies in the prognosis of acute pancreatitis. Rev Esp Enferm Dig 2002;94:406-16.

17 Windsor JA, Fearon KC, Ross JA, et al. Role of serum endotoxin and antiendotoxin core antibody levels in predicting the development of multiple organ failure in acute pancreatitis. Br J Surg 1993;80:1042-6.

18 Juvonen PO, Alhava EM, Takala JA. Gut permeability in patients with acute pancreatitis. Scand J Gastroenterol 2000;35:1314-18.

19 Ammori BJ, Leeder PC, King RF, et al. Early increase in intestinal permeability in patients with severe acute pancreatitis: correlation with endotoxemia, organ failure, and mortality. J Gastrointest Surg 1999;3:252-62.

20 Penalva JC, Martínez J, Laveda R, et al. A study of intestinal permeability in relation to the inflammatory response and plasma EndoCab lgM levels in patients with acute pancreatitis. J Clin Gastroenterol 2004;38:512-17.

21 Sainio V, Kemppainen E, Puolakkainen P, et al. Early antibiotic treatment in acute necrotising pancreatitis. Lancet 1995;346:663-7.

22 Such J, Frances R, Munoz C, et al. Detection and identification of bacterial DNA in patients with cirrhosis and culture-negative, nonneutrocytic ascites. Hepatology 2002;36:135-41.

23 Bradley EL III. A clinically based classification system for acute pancreatitis. Summary of the International Symposium on Acute Pancreatitis, Atlanta, Ga September 11 through 13, 1992. Arch Surg 1993;128:586-90.

24 Larvin M, McMahon MJ. APACHE-II score for assessment and monitoring of acute pancreatitis. Lancet 1989;2:201-5.

25 Balthazar EJ, Ranson JH, Naidich DP, et al. Acute pancreatitis: prognostic value of CT. Radiology 1985;156:767-72.

26 Lane DJ. 16S/23S rRNA sequencing. In: Stackebrandt E, Goodfellow M, eds Nucleic acid techniques in bacterial systematics. Winchester: John Wiley and Sons, 1991:115-75
27 Maidak BL, Cole JR, Lilburn TG, et al. The RDP-II (Ribosomal Database Project). Nucleic Acids Res 2001;29:173-4.

28 Altschul SF, Madden TL, Schaffer AA, et al. Gapped BLAST and PSI-BLAST: a new generation of protein database search programs. Nucleic Acids Res 1997:25:3389-402

29 Cicalese L, Sahai A, Sileri $P$, et al. Acute pancreatitis and bacterial translocation. Dig Dis Sci 2001;46:1127-32.

30 Arendt $T$, Wendt $M$, Olszewski $M$, et al. Cerulein-induced acute pancreatitis in rats - does bacterial translocation occur via a transperitoneal pathway? Pancreas 1997:15:291-6.

31 Ammori BJ, Fitzgerald P, Hawkey $P$, et al. The early increase in intestinal permeability and systemic endotoxin exposure in patients with severe acute pancreatitis is not associated with systemic bacterial translocation: molecular investigation of microbial DNA in the blood. Pancreas 2003;26:18-22.

32 Bittner R, Block S, Buchler M, et al. Pancreatic abscess and infected pancreatic necrosis. Different local septic complications in acute pancreatitis. Dig Dis Sci 1987;32:1082-7

33 Bradley EL III. A fifteen year experience with open drainage for infected pancreatic necrosis. Surg Gynecol Obstet 1993;177:215-22.

34 Farkas G, Marton J, Mandi Y, et al. Surgical strategy and management of infected pancreatic necrosis. Br J Surg 1996;83:930-3.

35 Luiten EJ, Hop WC, Endtz HP, et al. Prognostic importance of gram-negative intestinal colonization preceding pancreatic infection in severe acute pancreatitis. Results of a controlled clinical trial of selective decontamination. Intensive Care Med 1998;24:438-45

36 Al Soud WA, Radstrom P. Purification and characterization of PCR-inhibitory components in blood cells. J Clin Microbiol 2001;39:485-93.

37 Frances $\mathrm{R}$, Benlloch $\mathrm{S}$, Zapater $\mathrm{P}$, et al. A sequential study of serum bacterial DNA in patients with advanced cirrhosis and ascites. Hepatology 2004;39:484-91.

38 Klinman DM, Yi AK, Beaucage SL, et al. CpG motifs present in bacteria DNA rapidly induce lymphocytes to secrete interleukin 6, interleukin 12, and interferon gamma. Proc Natl Acad Sci U S A 1996;93:2879-83.

39 Lipford GB, Sparwasser T, Baver M, et al. Immunostimulatory DNA sequence-dependent production of potentially harmful or useful cytokines. Eur J Immunol 1997; 27:3420-6.

40 Yamamoto S, Yamamoto T, Kataoka T, et al. Unique palindromic sequences in synthetic oligonucleotides are required to induce IFN and augment IFNmediated natural killer activity. J Immunol 1992;148:4072-6.

41 Wagner $\mathrm{H}$. Interactions between bacterial CpG-DNA and TLR9 bridge innate and adaptive immunity. Curr Opin Microbiol 2002;5:62-9.

42 Frances R, Munoz C, Zapater P, et al. Bacterial DNA activates cell mediated immune response and nitric oxide overproduction in peritoneal macrophages from patients with cirrhosis and ascites. Gut 2004;53:860-4.

43 Krieg AM. CpG motifs in bacterial DNA and their immune effects. Annu Rev Immunol 2002;20:709-60.

44 Viedma JA, Perez-Mateo M, Agullo J, et al. Inflammatory response in the early prediction of severity in human acute pancreatitis. Gut 1994;35:822-7.

45 Norrby SR. Ecological consequences of broad spectrum versus narrow spectrum antibacterial therapy. Scand J Infect Dis Suppl 1986;49:189-95.

46 Kager L, Brismar B, Malmborg AS, et al. Effect of imipenem treatment versus imipenem surgical prophylaxis on the intestinal microflora. Int $J$ Clin Pharmacol Res 1988:8:441-7.

47 Shoda R, Mahalanabis D, Wahed MA, et al. Bacterial translocation in the rat model of lectin induced diarrhoea. Gut 1995;36:379-81.

48 Koyluoglu G, Bakici MZ, Elagoz S, et al. The effects of pentoxifylline treatment on bacterial translocation after hemorrhagic shock in rats. Clin Exp Med $2001 ; 1: 61-6$

$49 \operatorname{Kim} \mathrm{BN}$, Woo JH, Ryu J, et al. Resistance to extended-spectrum cephalosporins and mortality in patients with Citrobacter freundii bacteremia. Infection 2003;31:202-7.

50 Lew PD, Baker AS, Kunz $\sqcup$, et al. Intra-abdominal Citrobacter infections: association with biliary or upper gastrointestinal source. Surgery 1984;95:398-403.

51 Petakovic G, Korica M, Gavrilovic S. Bacteriologic examination of gallbladder contents. Med Pregl 2002;55:225-8.

52 Shih CC, Chen YC, Chang SC, et al. Bacteremia due to Citrobacter species: significance of primary intraabdominal infection. Clin Infect Dis 1996;23:543-9. 